\title{
A comunicação impressa nas áreas de proteção ambiental - estudo sobre o jornal da APA Lagoa Encantada, Ilhéus-Ba*
}

\author{
Eliana Cristina Paula Tenório de Albuquerque **
}

\section{Resumo}

A Área de Proteção Ambiental da Lagoa Encantada, instalada no município de Ilhéus-BA, abrange uma população superior a 23 mil pessoas, onde é aplicado produto comunicacional impresso, com a justificativa de informar, educar e sensibilizar os moradores para a conservação ambiental e a sustentabilidade. Este trabalho, ainda inicial, busca analisar se a estratégia de comunicação desenvolvida ali, por meio do jornal da $A P A$, é adequada à capacidade de recepção dos moradores daquele entorno - onde, segundo o IBGE, há $60 \%$ de analfabetos. Para tanto, toma como referência metodológica os aportes de Bauer e Gaskell (2002) sobre pesquisas qualitativas envolvendo textos, e enfatiza a análise de conteúdo do veículo em questão, no período compreendido entre janeiro e abril deste ano.

Palavras-chave: comunicação ambiental; jornalismo ambiental; estudo de conteúdo.

* Pesquisa inicial para dissertação de mestrado "Influência da Comunicação Impressa nas Áreas de Proteção Ambiental da Bahia - Estudo de Caso da APA da Lagoa Encantada" - Mestrado em Desenvolvimento Regional e Meio Ambiente do PRODEMA/ UESC, sob orientação dos Profs. Drs. Carlos Frederico B. Loureiro (UFRJ), André Luiz Belém (UNESP) e Paulo dos Santos Terra (UESC).

** Mestranda no curso de Desenvolvimento Regional e Meio Ambiente da UESC.

Comun. Inf., v. 6, n. 2, p.48-61, jul./dez. 2003 


\section{Criando as UCs}

A instalação das áreas naturais protegidas no Brasil remonta à década de 30 , mas foi somente nas décadas de 70 e 80 que a criação de Unidades de Conservação (UCs) ganhou impulso, chegando a existir 58 delas em território nacional, no final dos anos 80. Segundo Diegues (1997), o Brasil de 1990 contava com cerca de quinze tipos de UCs, englobando 429 unidades em nível federal, estadual e municipal, o que representava uma área de 48.720 .109 ha.

O processo de criação das UCs no Brasil, embora represente um considerável avanço para a conservação ambiental, aparece emaranhado em contradições e jogo de interesses. Uma das facetas desse jogo pode ser expressa no debts wapt for nature (conversão da dívida externa por conservação), explicado por Diegues (1997) como sendo uma espécie de negócio, onde parte da dívida externa de países do Terceiro Mundo "passa a ser adquirida (a taxas reduzidas) por entidades ambientalistas internacionais ou agências bilaterais, em troca da implantação de projetos conservacionistas pagos em moeda nacional pelo Governo". Assim, a criação das UCs passou a ser motivada não apenas pela real devastação de florestas e perda da biodiversidade, mas também por interesses econômicos, aqui expressos pela disponibilidade de fundos internacionais para a conservação e a possibilidade de geração de renda nessas áreas, por meio do chamado "turismo ecológico".

Com olhos nessa possibilidade, e logo após a promulgação da Constituição de 1988 - que passou a tratar a natureza como um bem coletivo e previu a criação de espaços especialmente protegidos -, 0 Governo da Bahia deu início à discussão para a implantação das Áreas de Proteção Ambiental do Estado, como parte do Programa de Desenvolvimento Turístico Integrado do Nordeste (Prodetur), apoiado em recursos do Banco Interamericano de Desenvolvimento(BID). Esse Programa, conforme explica seu projeto de implantação, formulado pela Secretaria da Cultura e Turismo de Estado (1997), propõe, mediante a criação de Complexos Turisticos Integrados, "o desenvolvimento e a ordenação da atividade turística na Bahia, tendo como base o seu significativo patrimônio natural, paisagístico e histórico-cultural".

Para estabelecer as condições de infra-estrutura adequadas ao desenvolvimento das atividades turísticas - e assegurar os investimen-

Comun. Inf., v. 6, n. 2, p.48-61, jul./dez. 2003 
tos previstos pelo BID -, o Governo do Estado criou as primeiras seis Áreas de Proteção Ambiental, ao longo da extensão litorânea baiana. Na zona turística ao sul do Estado - designada Costa do Cacau, local de Mata Atlântica ainda preservada, com muitos rios, manguezais e mar - foram estruturadas duas APAs: a de Itacaré-Serra Grande, criada em 7 de junho de 1993 e que envolve os municípios de Itacaré e Uruçuca; e a da Lagoa Encantada, situada ao norte de Ilhéus, em área que compreende 118 quilômetros quadrados, abarca uma população superior a 23 mil habitantes e foi criada em 15 de junho de 1993, por Decreto Municipal.

O Diagnóstico do Meio Físico, Biótico e Sócio-econômico daAPA da Lagoa Encantada, produzido pela V\&S Consultores para a Secretaria da Cultura e Turismo da Bahia (1996), justificou a escolha dessa área para implementação de uma UC, por possuir como ponto referencial a Lagoa Encantada, "local de grande beleza, com cachoeiras, cascatas, rios e florestas, além de um grande lago da água doce, com área aproximada de $6 \mathrm{~km} 2$ e paisagem semelhante à da região amazônica", inclusive no que se refere às características etnológicas de seus habitantes, hábitos culturais e atividades econômicas, onde a caça, a pesca, o extrativismo e os cultivos de subsistência se destacam, o que, certamente, poderiam ser bons atrativos para o turismo ambiental. Foram esses moradores, que estão espalhados nos 11 distritos, povoados e vilas do entorno da Lagoa, que passaram a nos interessar, especialmente porque, em que pese a sua simplicidade e falta de instrução básica - segundo o último senso do IBGE, $60 \%$ dessa população não é alfabetizada - é a eles que deve caber a execução das tarefas de conservação ambiental previstas no Projeto de Implantação da APA, sendo-lhes destinada a política de comunicação voltada para a educação ambiental e desenvolvimento sustentável, que tem como principal veículo um jornal impresso: o jornal da APA, denominado Em Cantos da Lagoa, que ora estamos analisando.

Partindo do raciocínio de que, por serem, em sua maioria, analfabetos, os moradores não poderiam ler um jornal ou qualquer outro veículo impresso e, por isso, estão sendo pesquisados o nível de informação apreendido por eles até então e qual o conteúdo apresentado pelo jornal, cujo objetivo oficial é informá-los/formá-los para que defendam seu habitat natural e, simultaneamente, promovam o desenvolvimento sustentável.

Comun. Inf., v. 6, n. 2, p.48-61, jul./dez. 2003 


\section{Realmente educando?}

O Projeto de Implantação da APA da Lagoa Encantada explicita, como já vimos, a necessidade de elaboração e realização de programas e campanhas de educação ambiental calcadas em materiais impressos, visando a conscientização das comunidades locais e regionais, e de turistas quanto à importância da preservação e conservação ambiental em geral e, em especial, no âmbito da APA. Observando essa premissa e o alto índice de analfabetismo naquela área, pode-se questionar até que ponto é eficaz a política comunicacional voltada para os meios impressos, uma vez que ela está direcionada para um público que pode não estar preparado para recebê-la.

Bordenave (2001) assegura que "a comunicação não é um ato isolado ou uma série de atos individuais desconexos, mas um fluxo contínuo de muitas origens e direções, com conteúdos e formas em constante mutação", o que não vem sendo feito ali. Nesse sentido, Ramos (1995) defende ser importante "investigar de que forma vem se dando a participação da comunicação de massas no processo de discussão dos problemas ambientais com o objetivo de fornecer subsídios para a complementação de programas de educação ambiental". Segundo ele, a possibilidade de conscientização para uma melhoria da qualidade de vida está diretamente ligada à eficiência dos meios de comunicação em atingir o público específico e necessário. Será que, no caso em estudo, isso vem ocorrendo?

Por sua vez, Miége (2000) argumenta que "um grupo social negocia sua recepção a partir de sua cultura própria, com o que ela tem de memória social especifica, de conhecimentos armazenados, de grandes expectativas, de recursos simbólicos". Ou seja, o processo de comunicação só se realiza quando há uma identificação entre receptor, emissor, meio e mensagem, linguagem e cultura. Quando há afinidades. Diante disso, cabe investigar qual a afinidade que há entre o morador do entorno da APA, o conteúdo e formato do material produzido; o tipo de linguagem que é utilizada; se as mensagens recebidas por meio do jornal daAPA são decodificadas, como o são e por quem; quais as ações concretas e educativas geradas à partir dessa decodificação e qual a opinião dos moradores sobre o referido veículo.

Para responder a isso, a pesquisa, ainda em fase inicial, começou por analisar o conteúdo dos últimos exemplares produzidos e realizou

Comun. Inf., v. 6, n. 2, p.48-61, jul./dez. 2003 
entrevistas com alguns atores desse processo: vários moradores, um dos redatores do jornal e um membro do Conselho Gestor da APA. São os resultados deste trabalho, ainda em sua fase inicial, que estão sendo apresentados aqui.

\section{A pesquisa}

O Jornal da APA - O jornal Em Cantos da Lagoa, veículo oficial de divulgação daAPA da Lagoa Encantada, vem sendo editado mediante convênio entre o Centro de Recursos Ambientais do Governo do Estado da Bahia (CRA) e a organização não-governamental Associação Pró-Bacia do Rio Almada (ABARA), desde o início de 2001. É uma publicação trimestral, com 8 páginas em tamanho tablóide, impressas em papel $40 \mathrm{~kg}$ branco, com capa e contracapa em policromia, miolo em preto e branco e tiragem de 3 mil exemplares, o que corresponde à população de apenas um dos 11 povoados que fazem parte do entorno em estudo.

Foram analisados os exemplares editados em janeiro e abril de 2003 , nos quais percebe-se algumas características de paginação que dificultam a leitura, principalmente de quem não sabe ler fluentemente.

Os moradores - Dividida entre 11 lugarejos, que são denominados de distritos, povoados ou vilas, a população do entorno daAPAé expressiva: mais de 23 mil habitantes. Para ouvir suas opiniões sobre o jornal, foram escolhidos nesta etapa os povoados de Vila das Areias, onde fica a Lagoa, e de Vila Juerana, primeiro lugarejo por onde passa a rodovia BA-001, que liga Ilhéus a Itacaré, e que foi construída para ser uma "estrada ecológica", de preservação da vida. Tanto assim que tem passarelas para macacos, túneis para guaiamuns e caranguejos, e cipós para micos atravessarem a pista, entre outras novidades. Só não tem passarelas para pedestres, o que a transforma, ironicamente, em recordista regional de mortes por atropelamento. Nos últimos dois anos, segundo dados fornecidos pela Polícia Rodoviária Estadual, 14 pessoas morreram atropeladas nas margens da estrada. Entre elas, nove eram crianças.

$\mathrm{Na}$ Vila das Areias, localidade com quase 1000 habitantes, foram entrevistadas 20 pessoas. Em Vila Juerana, que tem quase 600 habitantes, foram feitas 12 entrevistas. Em todas foram feitas as mesmas perguntas sobre o jornal da APA, que estão devidamente gravadas e arquivadas para posterior análise, junto com as que forem feitas nos

Comun. Inf., v. 6, n. 2, p.48-61, jul./dez. 2003 
demais lugarejos a serem pesquisados no decorrer do trabalho de mestrado.

\section{Resultados}

\section{Análise de conteúdo do jornal}

- A capa (página 1) vem sempre com uma fotografia de página inteira e três pequenas chamadas consideradas principais, em corpo 10. Não há títulos grandes ou textos longos. Apenas as chamadas para as páginas internas, soltas sobre a foto.

- A página 2 é repartida em três pedaços. Os principais, que ocupam $2 / 3$ da página, são: um editorial, em corpo 9 , fonte Times New Roman e, em média, 670 palavras, com termos como "diminuta amplitude de soluções" ou "salvaguardando-se a premissa", que estão distantes do vocabulário local; e uma pequena matéria sobre curiosidades, como a formação da palavra Sambaituba (que dá nome a um dos povoados) ou o folclore da Lagoa, que é repleto de mitos e seres imaginários. Compōsta em corpo 10, essa matéria não contém qualquer fotografia ou desenho, tornando a leitura cansativa. A linguagem utilizada, apesar de ser mais popular, ainda usa termos como "inopinadamente", "complacentes" e "convincentes'. Todos os títulos são em letra de estilo artístico, caixa alta e corpo oscilando entre 18 e 20, de dificil leitura ęm jornais.

- O restante da página 2 é preenchido por um gigantesco expediente, onde constam os dados convencionados para qualquer expediente, além das logomarcas, em tamanho grande, do Governo da Bahia, CRA e ABARA. O tamanho dessas logomarcas é desproporcional ao do texto do expediente.

- Analisando o expediente pudemos perceber que só há um jornalista na equipe, que é também o editor. Os demais participantes do projeto são membros da ONG ou do CRA e não são profissionais da área de comunicação, mas apenas interessados (e nem sempre especialistas) em questões ambientais. São eles os responsáveis por algumas entrevistas e muitas fotografias.

- A página 3 contém também três partes: uma com matéria informativa sobre o trabalho da Universidade Estadual de Santa Cruz (UESC) em alguma das comunidades da APA, em corpo 10 e com

Comun. Inf., v. 6, n. 2, p.48-61, jul./dez. 2003 
400 palavras em média. Aí já são utilizadas fotos em preto e branco, mas o título e a linguagem continuam no padrão anterior, com termos como "atividades extracurriculares", "dados aferidos" e "medidas profiláticas", que são utilizados abundantemente. A seguda parte é ocupada por uma matéria técnico-científica sobre alguma espécie da fauna ou flora nativa, sendo que aí, além de o corpo da letra ser 10, os termos extrapolam o bom senso e caminham em construções lingüísticas complicadas para o entendimento nativo, como "sob o abdômem", "percentual de fêmeas ovadas nas amostras", "as espécies estão se ressentindo" e outras que são utilizadas para descrever, por exemplo, uma simples andada de caranguejo semiterrestre da espécie Cardisoma ganhumi, muito popular no local como guaiamum e fonte de renda para boa parte das comunidades ribeirinhas. A outra matéria é sempre vinculada a algum personagem da Lagoa: um velho pescador, uma lavadeira, um jovem promissor, enfim, gente do lugar. Está sempre restrita a menos de 50 palavras, em um pequeno box entre fios, letra com corpo 9 e uma minúscula foto do personagem. Espaço bem maior é destinado à propaganda, colocada no rodapé, do Centro de Informações Turístico-Ambientais, que foi montado nas redondezas pelo governo do Estado.

- As páginas centrais (4 e 5) vêm com duas entrevistas de moradores dos maiores dentre os 11 povoados. E não trazem grandes novidades: apenas elogios à gestão da APA ou ao trabalho de alguém, críticas sobre a vizinhos que não ajudam a preservar, e assim por diante, o que denota uma certa parcialidade na escolha dos entrevistados. As entrevistas são feitas no formato perguntas/respostas e editadas em corpo 10, o que continua deixando a leitura difícil e cansativa até para quem gosta de ler. Há apenas uma foto de cada entrevistado, em tamanho pequeno e colocada em um círculo no meio da página, o que lhe dá a estranha aparência de homenagem pós-mortem.

- A página seguinte é dedicada à gerência da $\mathrm{APA}$, que, usando corpo 10 em texto com cerca de 820 palavras, deixa pouco espaço para as duas fotografias: uma no canto esquerdo superior, com a imagem da gerente, e outra ao centro, com uma imagem da Lagoa, a mesma observada na primeira página, só que em tamanho muito reduzido.

- A penúltima página repete os mesmos erros das outras: usa corpo 10 em todas as matérias, excesso de palavras e pouquíssimas ilustrações. É dividida ao meio, no sentido vertical. Na primeira meta-

Comun. Inf., v. 6, n. 2, p.48-61, jul./dez. 2003 
de há uma entrevista no estilo perguntas e respostas com um velho morador de algum povoado, que conta histórias antigas do lugar. $\mathrm{Na}$ outra metade, um texto técnico-científico com engenheiros ligados aos governos municipal ou estadual, que utilizam frases como "a florística está representada para as florestas ombrófilas densa e estacional semidecidual" ou "Epífitas, se existentes, são representadas principalmente por líquens, briófitas e pteridófitas com baixa densidade". Frases que dispensam qualquer comentário, em se tratando de tentar obter o entendimento popular.

- Por fim, na última página, há um verdadeiro desperdício de espaço: apenas uma propaganda mal estruturada sobre um trabalho feito pela ONG com uma das comunidades locais. Sem fotos, sem apelos, sem títulos impactantes, sem objetividade, tudo muito "sem". Foge da "criatividade, objetividade, forma e expressão", indicadas por Sant'anna como requisitos de uma boa propaganda.

- Foi observado que, em todas es edições, não há uma única matéria em linguagem coloquial, voltada para o entendimento do morador local, parecendo que o jornal é mais destinado a um público acadêmico que a um público composto por populações nativas e pouco alfabetizadas.

- Também foi constatado que não há uma preocupação gráfica adequada. A diagramação é densa, carregada, utiliza títulos em corpo e famílias que dificultam a leitura em jornais e possuem pouco impacto, assim como faz uso de corpo muito pequeno (geralmente 9 ou 10), para os textos e entrevistas, que são editados no tipo de letra Times New Roman. Esse tipo faz parte de uma família de letras que já tem na sua característica o fato de possuir um tamanho pequeno, tanto que, quando usada em jornais (e muitos o usam), isto é feito geralmente em corpo 11.

- Não há qualquer preocupação estética ou visual. Não são utilizadas técnicas capazes de dar leveza ao texto, especialmente no que se refere à arte gráfica ou ao uso de imagens, como fotografias e desenhos. Não há divisão adequada de colunas, que são muito largas; os títulos possuem corpo inexpressivo (geralmente 14, 18 ou 20), enfim, não há preocupação com o uso de técnicas que possam transformar um projeto qualquer em um indispensável projeto para conscientização ambiental, capaz de atingir o coração e a mente do seu público principal, que são os moradores da APA. Nesse caso específico, onde o público é composto por uma maioria que não sabe

Comun. Inf., v. 6, n. 2, p.48-61, jul./dez. 2003 
ler, as imagens tornam-se muito mais expressivas que o próprio texto, que passa a ser basicamente informativo-explicativo.

\section{Análise das entrevistas com moradores}

\section{Em Vila das Areias}

Das 20 entrevistas feitas em Vilas das Areias, $25 \%$ dos entrevistados disseram que lêem regularmente o jornal e entendem seu conteúdo. Desses, $15 \%$ são pequenos empresários, ligados ao turismo local e $10 \%$ são donos de casas no local, mas não são nativos. Dos outros $75 \%$ dos entrevistados - dentre os quais $65 \%$ são nativos e $10 \%$, dentre moradores mais recentes $-50 \%$ admitiram que não sabem ler e $25 \%$ disseram que não entendem o conteúdo do jornal.

Algumas entrevistas são bem inusitadas: um pequeno agricultor, que vive da mandioca e da farinha que produz com ela, disse que, apesar de não saber ler, "gosta de ver o jornal porque tem gente conhecida nas fotos". Mas confessou que "não sabe de nada do que está escrito" e disse que depois que olha as fotos, guarda o jornal para servir como "forro de esteira em dias de frio"; Uma proprietária de bar disse que lê pouco "porque trabalha muito e não tem tempo". O filho dela desmentiu dizendo que ela "não lê nada porque não sabe". Nem ele. Contou ainda que "é dificil achar o jornal na Lagoa". Um microempresário ligado ao turismo disse que "ojornal é muito interessante porque fala da realidade local, mas que usa uma linguagem rebuscada demais para ser entendida pela população nativa". E arriscou: "Parece que ele é mesmo feito para quem tem muita instrução".

Uma adolescente, nativa da Vila e cursando o primeiro grau, disse que não lê o jornal porque não consegue "entender direito os termos". Precisaria ler muitas vezes e ela não tem tempo. Quem usa mesmo o jornal, quando ele aparece, é o pai, pescador, que o "leva para a feira de Ilhéus para enrolar o peixe que é vendido àqueles que não levam sacola". Um antigo proprietário de pousada é ainda mais contundente. Segundo afirmou, "o jornal não tem por finalidade esclarecer a população porque não interessa ao governo municipal nem ao estadual que isso ocorra. Quanto mais sem informação for uma população, mais facilmente ela poderá ser manipula$d a^{\prime \prime}$.

Comun. Inf., v. 6, n. 2, p.48-61, jul./dez. 2003 


\section{Em Vila Juerana}

Dos 12 entrevistados, apenas $25 \%$ conhecem o jornal. Os demais (75\%) nunca o tinham visto nem sabiam da sua existência. Entre os $25 \%$ que o conhecem, apenas $8,3 \%$ já o haviam lido. Os outros $16,7 \%$ disseram que não sabem ler. Ou seja, já viram o jornal, mas não o leram.

O único morador que leu o jornal é um biólogo, que está no local há pouco mais de dois anos e para quem "a linguagem é muito técnica e não permite que a população nativa a compreenda". Disse ainda que, diante da expressividade populacional da APA, "a tiragem é reduzida e o projeto gráfico não oferece qualquer atrativo a mais para o leitor". Sua conclusão é que "isso deve dificultar a leitura".

\section{Análise das demais entrevistas}

Com esses dados, a segunda parte desta pesquisa foi ouvir os produtores do jornal. Conseguimos localizar, por telefone, apenas um deles, que falou sobre as dificuldades encontradas na elaboração do jornal. "Os colaboradores são de outras áreas, mais ligadas à agronomia, turismo, biologia... com exceção do editor, que é um jornalista". Isso pode explicar a falta de critérios na diagramação, a qualidade suspeita das fotos e a falta de codificação adequada das mensagens para que possam ser entendidas pelos nativos. Estes correspondem a 96,5\% da população fixa da APA, segundo dados da Secretaria da Cultura e Turismo da Bahia, que implantou o projeto. Deve explicar também a falta de mobilização dessas comunidades em defesa do seu patrimônio natural que, apesar de estar dentro de uma APA, continua sendo degradada, especialmente pelo turismo predatório e por falta de estratégias para seu gerenciamento. A primeira iniciativa de análise nesse sentido é uma pesquisa de mestrado, que ainda está também em fase inicial.

Com isso, justificam-se as palavras de Bernardo Toro quando diz que "toda mobilização social requer um projeto de comunicação na sua estruturação" (1997). Se não há uma estratégia de comunicação adequada à realidade da população do entorno da Lagoa Encantada, certamente a mobilização social aí não se completa. Fica solta, desconectada, sem rumo e sem receptores, como está sendo constatado aqui.

Comun. Inf., v. 6, n. 2, p.48-61, jul./dez. 2003 
A última etapa deste trabalho foi a busca de informações sobre o tema no Conselho Gestor da APA, formado por entidades oficiais, ONGs e moradores representantes dos lugarejos. Um deles admitiu que o jornal da APA "não é muito direcionado para a população nascida e criada aqui". Disse que tem a impressão de ser ele apenas "uma prestação de contas do que está sendo feito aqui pela parceria do governo com a $O N G$ ", mas acha que não visa educar ou conscientizar a população. Se assim fosse, "a escrita seria outra, mais fácil e menos complicada". Segundo afirmou ainda, o Conselho Gestor não participa do jornal, principalmente porque "os que são daqui são pessoas simples, sem muita letra", que não têm muito como colaborar. Os que têm mais instrução, arriscam uma ou outra contribuição, mas nada organizado ou sistemático. "Quem faz tudo são os que sabem mais ...", concluiu.

\section{Conclusões}

Com base nas análises do material e das entrevistas, conclui-se que a forma de comunicação que vem sendo utilizada na APA não é eficiente para cumprir o papel a ela destinado pelo projeto original e reforçado pela Agenda 21, nacional (2000) e local (2001), de ser um agente a serviço da educação ambiental, da informação e da conscientização dos nativos e dos turistas. Como disse um dos entrevistados da Vila das Areias, "as pessoas não têm consciência, estão apenas acostumados. Sabem que, se cortarem a mata, o Ibama prende e se invadirem o manguezal, a prefeitura vem com a policia e tira todo mundo de lá. Por isso, todo mundo vai se acostumando com as leis. Mas isso não é consciência, é?". Realmente, não se pode dizer que seja. Logo, o principal papel do jornal daAPA, que é a conscientização da população para a defesa do meio ambiente e dos recursos naturais, ao que indica esta pesquisa, não está sendo cumprido.

Espera-se, com o decorrer deste trabalho de pesquisa, formar as bases para a avaliação da realidade atual, no que se refere à qualidade da informação veiculada oficialmente. A partir daí, construir novos modelos comunicacionais que estejam ajustados à capacidade de recepção do público específico e aos parâmetros propostos pela Agenda 21 nacional e local, sendo capazes de gerar um grau adequado de conscientização ambiental, construção da sustentabilidade e da cidadania.

Comun. Inf., v. 6, n. 2, p.48-61, jul./dez. 2003 


\section{Abstract}

The Ambiental Protection Area of Lagoon Enchanted, located in Ilhéus city, in the state of Bahia, has a population superior of 23 thousand people, there is applied the communicational press product, with the aim of inform, educate and to touch the local population in order the preserve the environment and sustainability. The present work, in the initial phase, intends to analyze if the communication strategy developed there through APA journal is adequate to capacity of reception if the local people - where, according the IBGE, there are $60 \%$ of illiterates. As methodological reference, this paper takes the authors Bauer \& Gaskell (2002) when they write about qualitative researchers involving text, and emphasizes the analyses of the vehicle contents in question, in the period from January to April in the current year. contents.

Key words: comunication ambiental; journalism ambiental; study of the

\section{Referências}

ALBUQUERQUE, Eliana. et al. Jornalismo Regional: do coronelismo à subserviência. In: Resumo de Pesquisa. Santa Catarina: UESC, 2003.

BAUER, M.; GASKELL, G. Pesquisa qualitativa com texto, imagem e som: um manual prático. Tradução Pedrinho Guareschi. Petrópolis: Vozes, 2002. 516 p. BARZOTTO, V. H.; GHILARDI, M. I. Mídia, educação e leitura. São Paulo: Anhembi-Morumbi, 1999.240p.

BELLONI, M. L. O que é mídia-educação. São Paulo: Autores Associados, 2001. 100 p. (Polêmicas do Nosso Tempo).

BERRENSTEIN, S. G. Ecoturismo e comunicação: quem não se comunica, se trumbica. Salvador: Secretaria da Cultura e Turismo, 2002. 192 p.

BORDENAVE, J. E. D. Além dos meios e mensagens. Rio de Janeiro: Vozes, 2001.119p.

BOTÃO, P. R. Mídia Comunitária: novas tecnologias e a emergência do local. Trabalho apresentado no NP12. In: CONGRESSO ANUAL EM CIÊNCIA DA COMUNICAÇÃO DA INTERCOM, 25., 2002, Salvador. Núcleo de pesquisa comunicação para a cidadania. Salvador: Intercom, 2002.

BOUGNOUX, D. Introdução às ciências da informação e da comunicação. Rio de Janeiro: Vozes, 2002.

CARVALHO, I. C. M. A invenção ecológica: narrativas e trajetórias da educação ambiental. Rio Grande do Sul: UFRGS, 2001.229 p.

CHIZZOTTI, A. Pesquisa em ciências humanas e sociais. 3. ed. São Paulo: Cortez, 1998.

COMISSÃO MUNDIAL SOBRE MEIO AMBIENTE E DESENVOLVIMENTO. Nosso futuro comum. 2. ed. Rio de Janeiro: Fundação Getúlio Vargas, 1991. $430 \mathrm{p}$.

DEMO, P. Metodologia do conhecimento científico. São Paulo: Atlas, 2000.216 p. . Avaliação Qualitativa. Campinas: Autores Associados, 1999.

Comun. Inf., v. 6, n. 2, p.48-61, jul./dez. 2003 
DIEGUES, A. C. (Org.). Etnoconservação: novos rumos para a proteção da natureza nos trópicos. São Paulo: Hucitec, 1997. 169 p.

. O mito da natureza intocada. São Paulo: Hucitec, 1997. 169 p.

$\overline{\mathrm{DINES}}$, A. O papel do jornal: uma releitura. 6. ed. São Paulo: Summus, 186. $157 \mathrm{p}$.

FESTA, R.; LINS DA SILVA, C. E. Comunicação popular e alternativas no Brasil. São Paulo: Paulinas, 1986. 226 p.

GOVERNO DO ESTADO DA BAHIA. Diagnóstico do meio físico, biótico e sócio-econômico da área de proteção ambiental da Lagoa Encantada. Salvador: SCT/CODETUR, 1996. $139 \mathrm{p}$.

. Projeto de implantação das áreas de proteção ambiental de ItacaréSerra Grande, Lagoa Encantada e do Parque Estadual do Conduru. Salvador: SCT/CODETUR, 1997.41 p.

GOVERNO MUNICIPAL DE ILHÉUS. Agenda 21 de Ilhéus: rumo ao século XXI. Ilhéus: Editora da Universidade Livre do Mar e da Mata, 2002. 103 p.

HABERMAS, J. Consciência moral e agir comunicativo. Rio de Janeiro: Tempo Brasileiro, 1989.

HEEMANN, A.; FLORIANE, D. (Org.). Desenvolvimento e meio ambiente: teoria e metodologia em meio ambiente e desenvolvimento, n. 1. Paraná: UFPR, 2000. 105 p.

MAFFESOLI, M. Elogio da razão sensível. Petrópolis: Vozes, 1998.

MARCONDES FILHO, C. Quem manipula quem. Petrópolis: Vozes, 1986

MELO, J. M. Teoria da comunicação: paradigmas latino-americanos. Petrópolis: Vozes, 2000.

. Imprensa comunitária no Brasil. In: Comunicação \& sociedade. São Bernardo do Campo: Umesp, n. 2, p. 50-70, 1979.

. Papel da comunicação no desenvolvimento das populações rurais. In: Cadernos de jornalismo e comunicação, Rio de Janeiro, n. 24, p. 59-64, maio/ jun. 1970.

MANN, P. H. Métodos de investigação sociológica. Tradução Octávio A. Velho. 5. ed. Rio de Janeiro: Zarah, 1983. 198 p.

MIĖGE, B. O pensamento comunicacional. Rio de Janeiro: Vozes, 2000. 141 p. MINISTÉRIO DO MEIO AMBIENTE . Agenda 21 Brasileira: ações prioritárias. Brasília, 2000.191 p.

MORIN, E. Ciência com consciência. Rio de Janeiro: Bertrand Brasil, 1996.

PERUZZO, C. M. K. Comunicação nos movimentos populares: a participação na construção da cidadania. 2. ed. Petrópolis: Vozes, 1999. 342 p.

. Mídia comunitária. In: Comunicação \& sociedade. São Bernardo do Campo: Umesp, n. 30, p. 141-156, 1998.

PIGNATARI, D. Informação, linguagem e comunicação. São Paulo: Perspectiva, $1984.139 \mathrm{p}$.

RABELO, D. C. Comunicação e mobilização social: a agenda 21 local de Vitória (ES). 2002. Tese (Doutorado em Comunicação Social) - Universidade Metodista de São Paulo, São Bernardo do Campo. 2002.

RAMOS, L. F. A. Meio ambiente e meios de comunicação. São Paulo: Annablume, $1995.159 \mathrm{p}$.

Comun. Inf., v. 6, n. 2, p.48-61, jul./dez. 2003 
RUBIM, A. A. C. Novas configurações da política na idade mídia. Salvador: UFBA. 1997.

RUDIO, F. V. Introdução ao projeto de pesquisa científica. Petrópolis: Vozes, 1986. 144 p.

SANT'ANNA, A. Propaganda: teoria, técnica e prática. 3. ed. São Paulo: Pioneira, 1981.

SPAARGAREN, G.; MOL, A. P. J. Sociologia, meio ambiente e modernidade modernização ecológica: uma teoria de mudança social. Traduçao Salvador D. P. Trevizan. Ilhéus: Editus, 2002.51 p.

SOUSA, M. W. (Org.). Sujeito, o lado oculto do refletor. São Paulo: Brasiliente, $1995.231 \mathrm{p}$.

THIOLLENT, M. Metodologia da pesquisa-ação. São Paulo: Cortez, 1986.

TORO, J. B. A.; WERNECK, N. M. D. Mobilização social: um modo de construir a democracia e a participação. Brasília: Ministério do meio ambiente, recursos hídricos e amazônia legal, 1997, 104 p.

TREVISAN, S. Sociedade-natureza: uma concreta e necessária integração. Rio de Janeiro: Papel Virtual Editora, 1999. 148 p.

VIOLA, E. J. et al. Meio ambiente, desenvolvimento e cidadania: desafio para as ciências sociais. São Paulo: Cortez Editora, 1998. 220 p.

Comun. Inf., v. 6, n. 2, p.48-61, jul./dez. 2003 